\title{
The Impact of Age Structure of a Country in Case Fatality of Covid-19
}

ISSN: 2578-0379

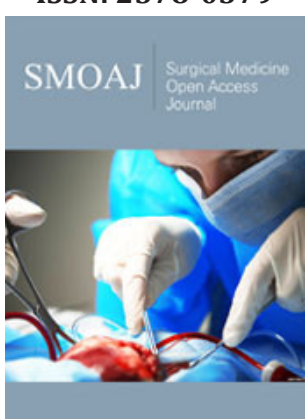

*Corresponding author: Anish TS, Department of Community Medicine, India

Submission: 㭗 November 20, 2020

Published: 侮 December 09, 2020

Volume 4 - Issue 1

How to cite this article: Hari prasad T, Anish TS. The Impact of Age Structure of a Country in Case Fatality of Covid-19. Surg Med Open Acc J. 4(1). SMOAJ.000578. 2020. DOI: $10.31031 /$ SMOAJ.2020.04.000578

Copyright@ Anish TS, This article is distributed under the terms of the Creative Commons Attribution 4.0 International License, which permits unrestricted use and redistribution provided that the original author and source are credited.
Hari prasad T and Anish TS*

Department of Community Medicine, India

Opinion

The SARS-CoV 2 pandemic, since its origin in China as a cluster of pneumonia cases, had reached almost every part of the world and had killed more than one million people worldwide [1]. The case fatality differs substantially between countries along with the number of symptomatic patients, sequelae of the disease and those who require intensive lifecare support. Such a perceived difference can be attributed to macroecological dissimilarities like the general well-being of the population and a more extent, its demographic structure. The demographic characteristics, most notably the age structure and population density, has important implications in the spread of infectious diseases [2,3]. Like most of the infectious diseases we have known so far, COVID-19 is seen more severely in groups like the elderly and those with comorbidities [4,5]. Robustness of the health system and abundance of resources might have helped the western countries to report proportionately a greater number of cases. However huge proportion of elderly population in these countries might have contributed to higher reporting of severe illness and deaths in these countries [6].

Here in this article, we compared the age-standardised proportion of COVID-19 fatalities out of the diagnosed cases across some selected countries of the world (Table 1). We used the published literature as the standardised age-specific risks in our analysis [4]. Demographic details of the countries were obtained from the respective census data. For the COVID-19 fatality data, we resorted to the WHO situation reports. The standardised infection fatality ratio is calculated from the age-specific fatality ratio as a weighted average [6].

Table 1: Impact of age structure of the country on impact of COVID 19.

\begin{tabular}{|c|c|c|c|c|}
\hline $\begin{array}{c}\text { Name of the } \\
\text { country }\end{array}$ & $\begin{array}{c}\text { Population } \mathbf{8 0} \\
\text { years } \mathbf{( \% )}\end{array}$ & $\begin{array}{c}\text { Age Standardised } \\
\text { IFR\# }\end{array}$ & CFR (Reported) & CFR/AS-IFR \\
\hline India & 8.5 & 0.4 & 1.49 & 3.7 \\
\hline UK & 22.6 & 1.15 & 4.45 & 3.8 \\
\hline Argentina & 14.4 & 0.71 & 2.65 & 3.7 \\
\hline USA & 18.5 & 0.94 & 2.52 & 2.7 \\
\hline Italy & 29.4 & 1.6 & 5.34 & 3.3 \\
\hline South Africa & 8 & 0.4 & 2.68 & 6.7 \\
\hline Brazil & 10.8 & 0.54 & 2.89 & 5.4 \\
\hline
\end{tabular}

\#Age-standardised IFR was calculated after applying the age-specific fatality ratios [4] over the respective population.

The age-standardised Infection Fatality Ratio (AS-IFR) ranges from 0.40 (India) to 1.6 (Italy) (Table 1). The country-wise ratio of the reported Case Fatality Ratio (CFR) as from the COVID-19 situation reports to the AS-IFR are almost comparable with a few exceptions, which may be attributed to other extraneous factors. The clinical endpoint of coronavirus disease is firmly dependant on the population age structure. A study from China reports that the CFR of the disease increases from $0.4 \%$ in patients in their forties to $14.8 \%$ for that above eighty years [7]. Italy also had a comparable fatality in the 40-50 age group while in the 
elderly (80+) the CFR has risen to $20.2 \%$ [8]. A higher perceived case adjusted mortality implies that a larger proportion of older adults are diagnosed as cases as the risk of dying in SARS CoV-2 increases with age. The age structure of the covid-19 patients, in turn, depends on that of the population, since the case numbers are very high. Italy is a country with a quarter of its population having their age above 65 years compared to fewer than $6 \%$ in India, which got reflected in their respective standardised fatality ratios. The age composition of the population, in different study settings, had explained up to three-quarters of variability in cross country CFR [9]. The economic wellbeing and national development which in turn have an effect on the surveillance system, its testing efforts and the quality, as well as the carrying capacity of the healthcare system, does also have a vital role in the reporting of cases and deaths. Acceptance of non-pharmacological preventive measures by the population and allegiance to the government in their disease containment measures are also factors of no less importance. Variability in the age-specific prevalence of comorbidities between populations can also contribute to the fairness of their reported CFR from the standardised IFR. Even with all these confounders, the age structure of the population had explained a major share of the interpopulation variability in COVID-19 mortality. Closeness to the age-adjusted infection mortality implies how good the national surveillance system in identifying the asymptomatic and mildly symptomatic cases which would have been passed over otherwise. The understanding of the importance of age structure in COVID-19 mortality gives us essential insights in adopting agespecific prevention strategies, including the reverse quarantine. The disproportionately higher case-fatality ratios reported by very few nations warrants further epidemiologic considerations. The governments are to be urged to follow the WHO recommendations and conduct seroprevalence assays to ascertain the cause of such extremes [10].

\section{References}

1. (2020) WHO Coronavirus Disease (COVID-19) Dashboard.

2. Yoshikura H (2015) Infectious disease, population size/density, and tax income of prefectures. Jpn J Infect Dis 68(5): 446-450.

3. Kashnitsky I, Aburto JM (2020) COVID-19 in unequally ageing European regions. World Dev 136: 105170.

4. Ferguson N, Laydon D, Nedjati G, Imai N (2020) Report 9: Impact of nonpharmaceutical interventions (NPIs) to reduce COVID19 mortality and healthcare demand.

5. Dowd JB, Andriano L, Brazel DM, Rotondi V, Block P, et al. (2020) Demographic science aids in understanding the spread and fatality rates of COVID-19. Proc Natl Acad Sci USA 117(18): 9696-9698.

6. (2020) Who situation reports.

7. Zhonghua L, Xing B, Za Z (2020) The epidemiological characteristics of an outbreak of 2019 novel coronavirus diseases (COVID-19). China CDC Wkly 2(8): 113-122.

8. Onder G, Rezza G, Brusaferro S (2020) Case-fatality rate and characteristics of patients dying in relation to COVID-19 in Italy. JAMA 323(18): 1775-1776.

9. Dudel C, Riffe T, Acosta E, Raalte A, Strozza C, et al. (2020) Monitoring trends and differences in COVID-19 case-fatality rates using decomposition methods: Contributions of age structure and age-specific fatality. PloS One 15(9): e0238904.

10.(2019) Population-based age-stratified seroepidemiological investigation protocol for coronavirus 2019 (COVID-19) infection. 